\title{
Room-temperature isomerization of 1-butene to 2-butene over palladium-loaded silica nanospheres catalyst
}

\author{
Yang Li, Chunyan Ma, Hongling Yang, Zhongshen Zhang, Xin Zhang, Nanli Qiao, Junhui Wang, \\ Zhengping $\mathrm{Hao}^{*}$
}

Department of Environmental Nano-materials and Technologies, Research Center for Eco-Environmental Sciences, Chinese Academy of Sciences, Beijing 100085, PR China University of Chinese Academy of Sciences, Beijing 100049, PR China

\section{H I G H L I G H T S}

- Study of the 1-butene isomerization at room temperature over supported Pd catalyst.

- The surface acidity of catalyst had remarkably influences on catalytic activity.

- Oxygen greatly enhanced the conversion without the formation of carbon dioxide.

- The butenylcarbenium ion intermediate determined the trans:cis ratio of 2-butene.

\section{A R T I C L E I N F O}

Article history:

Received 25 November 2015

Received in revised form 29 March 2016

Accepted 10 April 2016

Available online 16 April 2016

\section{Keywords:}

Palladium/silica nanospheres

1-Butene double-bond isomerization

2-Butene

Oxygen

Room-temperature reaction

\section{G R A P H I C A L A B S T R A C T}

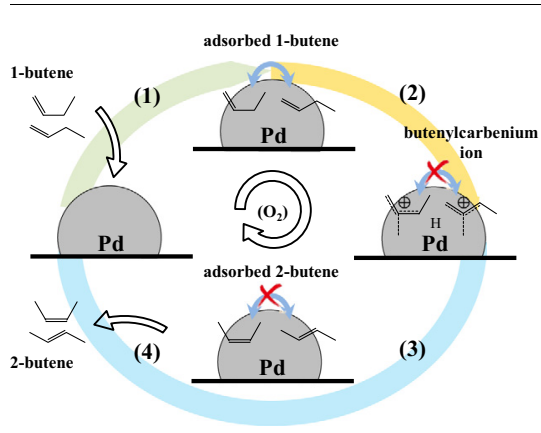

\begin{abstract}
A B S T R A C T
The traditional reaction temperatures of 1-butene isomerization to 2-butene tend to above $100{ }^{\circ} \mathrm{C}$, while here we report the unique catalytic performance of a Pd loaded silica nanospheres catalyst for 1-butene double-bond-shift isomerization at room temperature and showed 2-butene yield of 37.0\%. Furthermore, the introduction of $\mathrm{O}_{2}$ into the reaction mixture dramatically improved the yield efficiency to $57.2 \%$ without the formation of by-product $\mathrm{CO}_{2}$. The reaction process is proved that the ratio of trans-2-butene to cis2-butene in the final product was determined by the trans:cis ratio of the butenylcarbenium ion intermediate, and the ratio of trans-2-butene to cis-2-butene decreased with the increasing reaction temperature. Unlike other palladium catalyst systems, $\mathrm{Pd}^{0}$ nanoparticles were proved to act as catalytic active sites, and their oxidation and aggregation resulted in a decrease in activity. Most importantly, the catalyst acidity affected the catalytic performance, which provides theoretical basis for the choice of catalysts.
\end{abstract}

(c) 2016 Elsevier B.V. All rights reserved.

\section{Introduction}

Various chemical processes produce $\mathrm{C}_{4}$ cuts containing a substantial proportion of 1-butene. However, for some kinds of use, it is preferred to obtain a high content of 2-butene. For example,

* Corresponding author at: Department of Environmental Nano-materials and Technologies, Research Center for Eco-Environmental Sciences, Chinese Academy of Sciences, Beijing 100085, PR China. Tel./fax: +86 1062923564.

E-mail address: zpinghao@rcees.ac.cn (Z. Hao). in the HF-alkylation process of crude oil refining industry, 2butene is a better feedstock than 1-butene because 2-butene would lead a much lower amount of the less valuable dimethylhexanes $[1,2]$. What's more, as one of the major raw materials used in industrial organic chemistry, propene could also be obtained by the metathesis of 2-butene and ethene [3,4]. The isomerization of 1-butene to 2-butene is a green catalytic process and has become more attractive in terms of lower overall costs.

Due to the limited applications of 2-butene in past industrial processes, studies on butene have focused primarily on the skeletal 
isomerization of 1-butene to iso-butene [5-8] and the trans-cis isomerization of 2-butene [9-12]. Some earlier studies [13] focused on the thermodynamic date and reaction mechanism of 1-butene isomerization reaction. Although 2-butene is a thermodynamically stable isomer, a relatively high reaction temperature is needed to overcome the activation barrier for the isomerization of 1-butene. The thermodynamic equilibrium is unfavorable to the conversion of 1-butene to 2-butene at high temperature. Besides, the higher reaction temperature, the greater energy consumption and which will also produce extra exhaust emissions. The by-products of isomerization reaction such as $\mathrm{CO}_{2}$ are also easy to generate, therefore studies about introducing oxygen $\left(\mathrm{O}_{2}\right)$ into the reaction mixture have been rare. Running the isomerization reaction at room temperature allows the effects of $\mathrm{O}_{2}$ to be evaluated.

Perissinotto et al. [14] prepared a series of acid-leached metakaolin and tested the catalytic performance of 1-butene doublebond-shift isomerization. The highest conversion was about $90.0 \%$ with a selectivity of $71.7 \%$, even under the harsh reaction conditions $\left(T=400^{\circ} \mathrm{C}\right)$. Puriwat et al. [15] investigated the isomerization of 1 -butene over a $\mathrm{MgO} / \mathrm{Mg}(\mathrm{OH})_{2}$ catalyst at $300^{\circ} \mathrm{C}$, obtaining a conversion of only $20-70 \%$. Li et al. [16] synthesized Cs/ zeolite $\mathrm{X}$ catalysts and conducted the same reaction at $100^{\circ} \mathrm{C}$, attaining a relatively high conversion of 1 -butene (81\%). This reaction has also been examined in ionic liquids (e.g., EmimF [17] and EmimCl [18]) using computational methods. However, several challenges remain in performing the analogous experimental studies, and the use of ionic liquids severely restricts practical applications. Amigues et al. [19] developed supported noble metal (from group VIII of the periodic classification of elements) catalysts for isomerizing 1-butene to 2-butene from $50{ }^{\circ} \mathrm{C}$ to $140{ }^{\circ} \mathrm{C}$, while the catalyst should be pretreated using sulfur compound and subsequently hydrogen.

As a kind of those noble metals, palladium (Pd) has been used as a catalytically active phase in various organic synthesis, including cross-coupling reactions $[20,21]$ and hydrogenation reactions [22], and has shown excellent catalytic activity and selectivity. Palladium had also been proved to be active for 1-butene isomerization reaction at lower temperature. Sen et al. [23] used two different substrates, $\left[\mathrm{Pd}\left(\mathrm{CH}_{3} \mathrm{C}-\mathrm{N}\right)_{4}(\mathrm{BF})_{2}\right]$ and its tertiary phosphine derivatives as catalyst and $\mathrm{CH}_{3} \mathrm{CN}$ or $\mathrm{CHCl}_{3}$ were used as solvents. They found $\mathrm{Pd}^{2+}$ was the active site for 1-butene double-bond-shift isomerization reaction. Note that unlike the technique commonly used in industry, their work was conducted under homogeneous conditions, combined with the high costs of complex catalysts, determining that this reaction system will be difficult to be practically applied. Carrá et al. [24] employed supported Pd catalyst for 1-butene isomerization reaction from $160{ }^{\circ} \mathrm{C}$ to $240{ }^{\circ} \mathrm{C}$ and proved two different mechanisms, one of which showed a stereoselectivity towards cis-2-butene. Recently, Kominami et al. [25] developed a series of highly active $\mathrm{Pd} / \mathrm{TiO}_{2}$ catalysts prepared by a photodeposition method and conducted a 1-butene double-bond-shift isomerization reaction under UV irradiation. Unfortunately, no isomerization occurred in the dark (even at $70^{\circ} \mathrm{C}$ ) or under visible light.

The aforementioned studies seem to indicate that some amount of energy must be supplied (heat or light) to facilitate the isomerization of 1-butene to 2-butene. The current study describes the use of a supported Pd catalyst for the room-temperature isomerization of 1-butene without the addition of extra energy. Unlike the previous reports, we found $\mathrm{Pd}^{0}$ nanoparticles were also efficient for the titled reaction at room temperature. Furthermore, this study explores the influences of surface acidity and $\mathrm{O}_{2}$ on the double-bond-shift isomerization reaction.

\section{Experimental section}

\subsection{Chemicals and materials}

Palladium chloride $\left(\mathrm{PdCl}_{2}\right.$, Sinopharm Chemical Reagent Co., Ltd., AR), chloroauric acid ( $\mathrm{HAuCl}_{4} \cdot 4 \mathrm{H}_{2} \mathrm{O}$, Sinopharm Chemical Reagent Co., Ltd., AR), and chloroplatinic acid $\left(\mathrm{H}_{2} \mathrm{PtCl}_{6} \cdot 6 \mathrm{H}_{2} \mathrm{O}\right.$, Sinopharm Chemical Reagent Co., Ltd., AR) were used as noble metal precursors.

Silica nanospheres (SNS, Aladdin Reagent Co., Ltd., 99.5\%), Silicon dioxide $\left(\mathrm{SiO}_{2}\right.$, Degussa Co., Ltd., 99.8\%), H-BEA zeolite (Nankai University Catalyst Co., Ltd.), ZSM-5 zeolite (Nankai University Catalyst Co., Ltd.), aluminum sesquioxide $\left(\mathrm{Al}_{2} \mathrm{O}_{3}\right.$, Shandong Aluminum Co., Ltd.), and titanium dioxide nanopowder $\left(\mathrm{TiO}_{2}\right.$, Aladdin Reagent Co., Ltd., 99.5\%) were selected as supports.

Sulfuric acid $\left(\mathrm{H}_{2} \mathrm{SO}_{4}\right.$, Sinopharm Chemical Reagent Co., Ltd., GR) was used to treat with catalysts.

The reaction feed consisted of $5 \%$ butene (99.3\%) and various amounts of $\mathrm{O}_{2}$ in $\mathrm{N}_{2}$.

\subsection{Synthesis of catalysts}

Noble metal-loaded catalysts were prepared using an impregnation (IMP) [26] method. The total noble metal loading of prepared catalysts was kept at $1.0 \mathrm{wt}$.\%. In a typical procedure, $2 \mathrm{~g}$ of the support was impregnated with an aqueous solution of a noble metal precursor at the desired mass ratio and kept overnight. After drying at $100{ }^{\circ} \mathrm{C}$, the samples were soaked in $2 \%$ aqueous ammonia and washed with ultrapure water (18 $\mathrm{M} \Omega$ resistivity). After drying at $100{ }^{\circ} \mathrm{C}$ overnight, the catalysts were reduced in $\mathrm{H}_{2}$ at $300{ }^{\circ} \mathrm{C}$ for $3 \mathrm{~h}$, and then exposed in $\mathrm{N}_{2}$ to remove residual $\mathrm{H}_{2}$.

$\mathrm{Pd} / \mathrm{SNS}$ and $\mathrm{Pd} / \mathrm{SiO}_{2}$ catalysts were also leached with acid aqueous solution for further study. The catalysts were soak in $1 \mathrm{M} \mathrm{H}_{2} \mathrm{SO}_{4}$ aqueous solution for $20 \mathrm{~min}$, and then filtered to remove the residual solution. The catalysts were finally dried at $60^{\circ} \mathrm{C}$ for $2 \mathrm{~h}$ and labeled as catalyst- $\mathrm{H}_{2} \mathrm{SO}_{4}$.

All of the catalysts were crushed and sieved using 40 mesh prior to use.

\subsection{Catalytic activity measurements for butene isomerization}

Catalytic tests were performed using a fixed glass U-tube reactor ( $6 \mathrm{~mm}$ inner diameter) loaded with $0.20 \mathrm{~g}$ of catalyst. The Utube was wrapped with aluminum foil to simulate dark conditions and immersed in a water bath. The reaction feed flow rate was maintained at $20 \mathrm{~mL} \mathrm{~min}^{-1}$ [weight hourly space velocity (WHSV) of $6000 \mathrm{~mL} \mathrm{~g}^{-1} \mathrm{~h}^{-1}$ ]. The reactants and products were analyzed using an Agilent 7890A gas chromatograph equipped with a flame ionization detector (HP-PLOT $\mathrm{Al}_{2} \mathrm{O}_{3} \mathrm{~S}$ column) and a thermal conductivity detector (TDX-01 column).

The catalyst behavior was evaluated in terms of the following parameters, where $F$ is the molar flow rate and subscripts $i$ and $o$ indicate values measured at the inlet and outlet, respectively:

Conversion $^{1-\text { butene }}=\frac{F_{\mathrm{i}}^{1-\text { butene }}-F_{\mathrm{o}}^{1-\text { butene }}}{F_{\mathrm{i}}^{1-\text { butene }}} \times 100 \%$

Yield $^{2-\text { butene }}=\frac{F_{\mathrm{o}}^{2-\text { butene }}}{F_{\mathrm{i}}^{1-\text { butene }}} \times 100 \%$

Ratio $^{\text {trans:cis }}=\frac{\text { Yield }^{\text {trans-2-butene }}}{\text { Yield }^{\text {cis-2-butene }}}$ 


\subsection{Materials characterization}

The Zeta potential was measured on a Malvern Zetasizer 2000. The samples were dispersed in water and tested for three times.

$\mathrm{NH}_{3}$ temperature-programmed desorption ( $\mathrm{NH}_{3}$-TPD) experiments were conducted carried out on a Micromeritics Chemisorb 2720 apparatus in a range of room temperature to $600{ }^{\circ} \mathrm{C}\left(10^{\circ} \mathrm{C}\right.$ $\left.\mathrm{min}^{-1}\right)$. About $80 \mathrm{mg}$ samples were heated at $100^{\circ} \mathrm{C}$ in pure $\mathrm{He}$ for $3 \mathrm{~h}$, and $2.0 \% \mathrm{NH}_{3} / \mathrm{He}$ was fed to the reactor for $30 \mathrm{~min}$ at room temperature. Then pure He was fed to the reactor at $50 \mathrm{~mL} \mathrm{~min}^{-1}$ for 30 min to purge away any residual $\mathrm{NH}_{3}$. The samples were then tested in a pure He flow.

X-ray photoelectron spectra (XPS) were recorded with a Thermo ESCALAB 250 instrument using $\mathrm{Al} K_{\alpha}$ radiation. The base pressure was $5 \times 10^{-8} \mathrm{~Pa}$. Binding energies were calibrated using the $\mathrm{C}$ (1s) peak of contaminant carbon $(\mathrm{BE}=285 \mathrm{eV})$ as the standard and quoted with a precision of $\pm 0.2 \mathrm{eV}$.

$\mathrm{H}_{2}$ temperature-programmed reduction $\left(\mathrm{H}_{2}-\mathrm{TPR}\right)$ experiments were also studied on the Micromeritics Chemisorb 2720 apparatus in a range of room temperature to $250{ }^{\circ} \mathrm{C}\left(10^{\circ} \mathrm{C} \mathrm{min}-1\right)$. About $80 \mathrm{mg}$ samples were preheated at $120^{\circ} \mathrm{C}$ for $30 \mathrm{~min}$ and tested in a $\mathrm{H}_{2} /$ He flow (5\%, $50 \mathrm{~mL} \mathrm{~min}^{-1}$ ).

Field-emission scanning electron microscopy (FE-SEM) images were obtained on Hitachi SU 8020 equipment, with a tungsten electron source and an accelerating voltage from $1.0 \mathrm{kV}$.

High-resolution transmission electron microscopy (HR-TEM) micrographs were obtained with a JEOL 2011 instrument at an acceleration voltage of $200 \mathrm{kV}$. The specimens were prepared by ultrasonic dispersion in ethanol and evaporating a drop of the resultant suspension onto ultrathin carbon supporting films.

\section{Results and discussion}

\subsection{Catalytic performance of noble metal-supported catalysts}

As shown in Fig. 1, the Pd/SNS catalyst exhibited an excellent catalytic activity with a $47.6 \%$ yield of 2 -butene without the formation of by-products such as $\mathrm{CO}_{2}$. Gold ( $\mathrm{Au}$ ) and platinum (Pt) were inactive under the same reaction condition. When Pd was partially replaced by $\mathrm{Au}$ at a $\mathrm{Au}: \mathrm{Pd}$ mass ratio of $1: 1$, the decline in Pd loading resulted in a yield of only $21.8 \%$. It's worth noting that, the unreduced Pd/SNS catalyst was inactive at the same reaction condition, which is the difference from the reported $\mathrm{Pd}^{+\delta}$ catalyst systems [23].

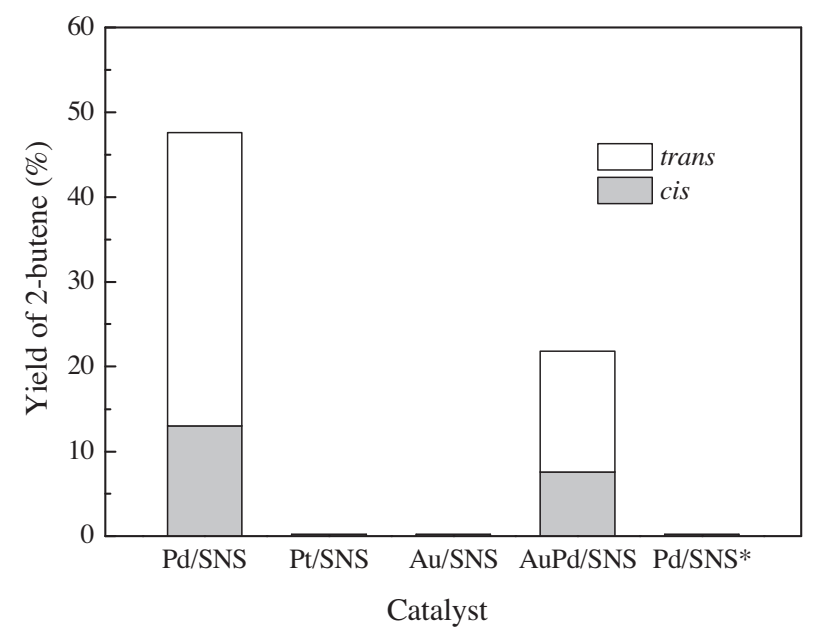

Fig. 1. Catalytic activities over various noble metal supported on SNS catalysts. The molar ratio of $\mathrm{O}_{2}: 1$-butene was $1: 1$ and the reaction temperature was $25^{\circ} \mathrm{C}$. The $\mathrm{Pd} /$ SNS* catalyst was not reduced by $\mathrm{H}_{2}$.
Other silica materials may be also efficient supports for this reaction (shown in Fig. 2). KIT-6 is a molecular sieve composed of pure silica [27], and the yield of 1-butene over Pd/KIT-6 was $21.2 \%$. A Pd/H-BEA catalyst exhibited a similar yield of $31.1 \%$. While Pd supported on other supports, even another kind of commercial silica material, exhibited nearly negligible activities for this reaction.

\subsection{Effect of the surface acidity on catalytic performance}

For supported Pd catalyst, there is a strong synergistic interaction between noble metal nanoparticles and support, which can greatly enhance the catalytic activity and selectivity [28,29], and the different catalytic activities resulted from supports, which could be partly explained by their corresponding Zeta potentials of those catalysts (shown in Fig. 2a). The Zeta potentials of active catalysts were below $-20 \mathrm{mV}$, suggesting the surface of those catalysts was acidic. According to Kominami's study, the UV irradiation is essential for 1-butene isomerization over $\mathrm{Pd} / \mathrm{TiO}_{2}$ under room temperature because it is a controllable substitute for the acidity of catalyst [25].

Total acidity measurements of catalysts were observed by $\mathrm{NH}_{3}$ temperature-programmed desorption and were shown in Fig. $2 \mathrm{~b}$. The catalysts exhibiting activities in 1-butene double-bond-shift isomerization reaction had an evident desorption peak of ammonia around $100{ }^{\circ} \mathrm{C}$. The peak can be assigned to $\mathrm{NH}_{3}$ adsorption on the
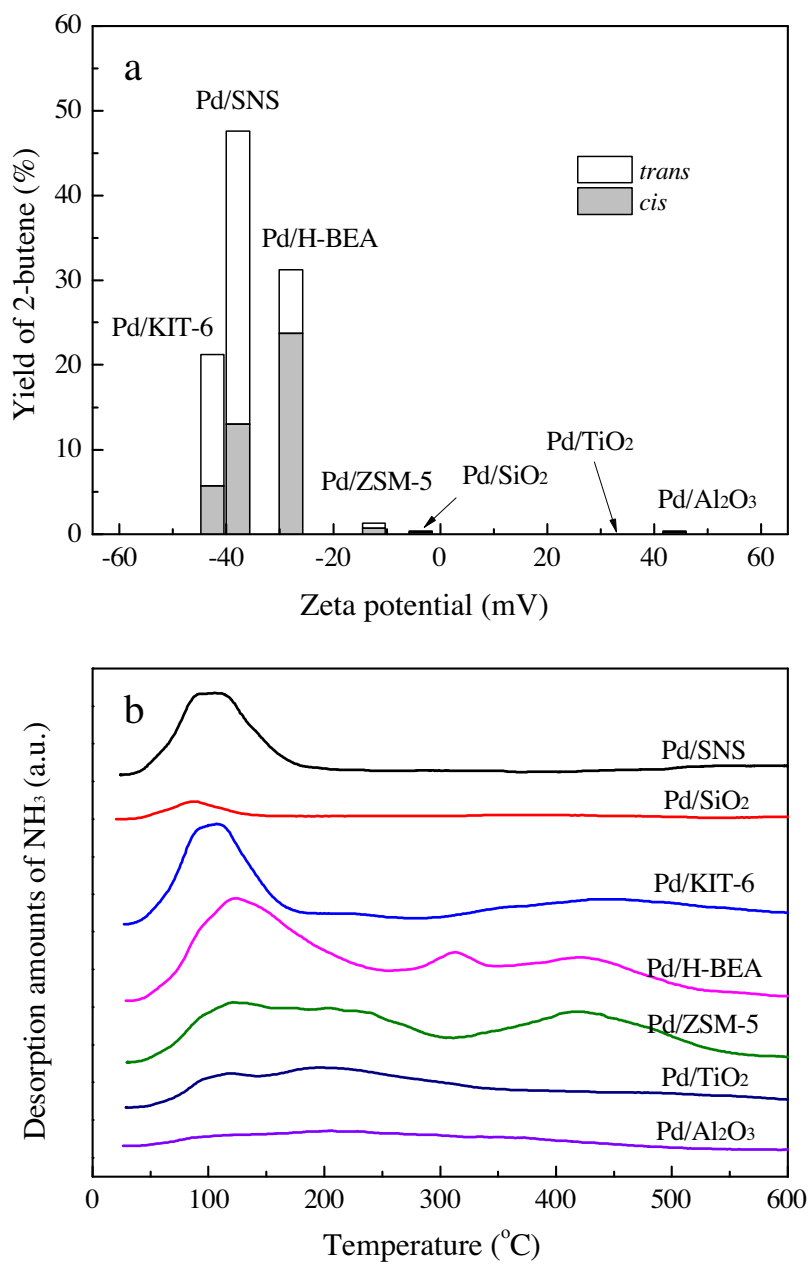

Fig. 2. Effect of the surface acidity on catalytic performance. (a) Correlation between catalytic activities and Zeta potential, and (b) $\mathrm{NH}_{3}$-TPD profiles of supported Pd catalysts. 
weak acid sites [30,31]. The peak area broadly increased with the yield of 2-butene enhanced, suggesting the surface weak acid sites have positive impacts on the catalytic performances as reported [32-34].

To further examine that the surface acidity of Pd-loaded catalysts has important effects on the catalytic activities, $1 \mathrm{M} \mathrm{H}_{2} \mathrm{SO}_{4}$ aqueous solution was used to leach the two kinds of catalysts carried in silica ( $\mathrm{Pd} / \mathrm{SNS}$ and $\left.\mathrm{Pd} / \mathrm{SiO}_{2}\right)$ and tested in the titled reaction at room temperature. As shown in Fig. S3, after the treatment, the yield of 2-butene over $\mathrm{Pd} / \mathrm{SiO}_{2}$ catalyst which was originally inactive increased to $43.9 \%$ and 1-butene almost completely convert to 2-butene over $\mathrm{Pd} / \mathrm{SNS}-\mathrm{H}_{2} \mathrm{SO}_{4}$ catalyst. This acid-leached method is effective for 1-butene double-bond-shift isomerization reaction and would be further studied.

\subsection{Influences of the reaction conditions}

The effects of reaction temperature and the presence of $\mathrm{O}_{2}$ on the catalytic activity of Pd/SNS catalysts were evaluated, and the results are shown in Fig. 3a. The double-bond-shift isomerization of 1butene was initiated at temperatures as low as $0{ }^{\circ} \mathrm{C}$. The only detected product was 2-butene and its trans:cis ratios were between 1.5 and 2.7, which decreased with increasing reaction temperature. Initially, the yield of 2-butene was about $37.0 \%$ at $25^{\circ} \mathrm{C}$. To the best of our knowledge, this is the highest yield efficiency reported at room temperature without light irradiation so far.
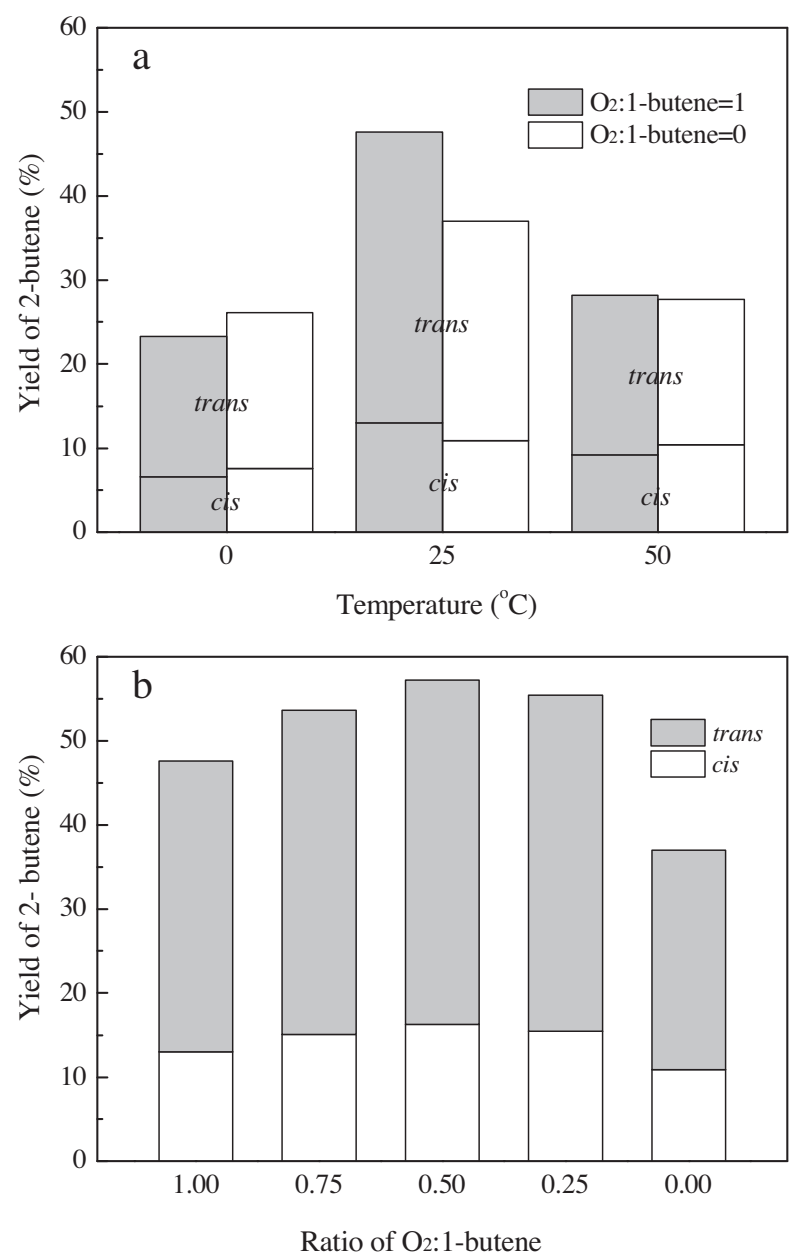

Fig. 3. Influences of the reaction conditions. (a) Catalytic activities over Pd/SNS catalyst at different reaction conditions at an $\mathrm{O}_{2}: 1$-butene ratio of $1: 1$, and (b) catalytic activities over Pd/SNS catalyst at $25^{\circ} \mathrm{C}$.
In the prior research, the effect of molecular $\mathrm{O}_{2}$ has never been evaluated in the catalytic conversion of 1-butene to 2-butene before because $\mathrm{O}_{2}$ seemed to have no positive effect on the isomerization reaction. More importantly, oxidizing gases can react with butene at high temperatures to yield unwanted by-products. We
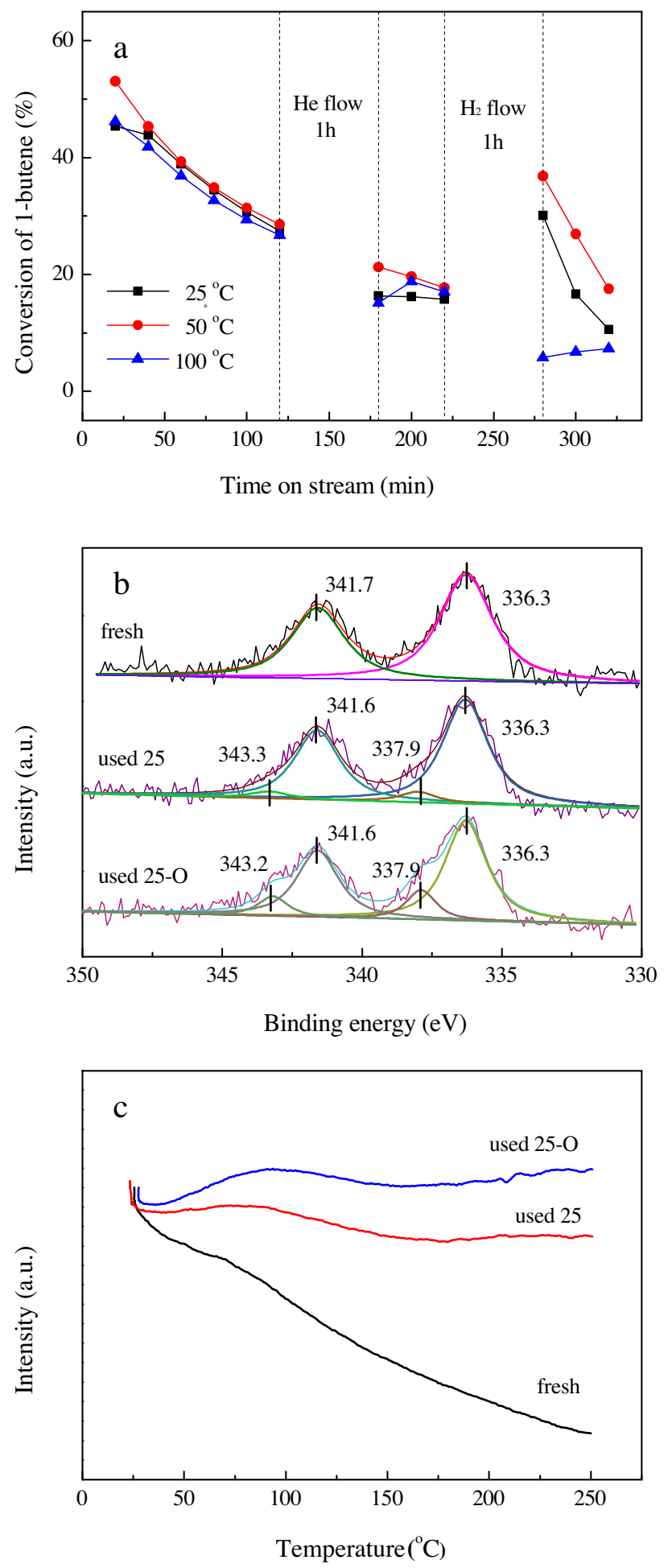

Fig. 4. Reasons for the decrease in catalytic activity. (a) The effects of sequential He and $\mathrm{H}_{2}$ exposures are shown on the catalytic performance of a Pd/SNS catalyst at an $\mathrm{O}_{2}$ :1-butene ratio of $1: 1$, (b) Pd (3d) XPS spectra and (c) $\mathrm{H}_{2}$-TPR patterns of the Pd/ SNS catalysts. Used catalysts are labeled with the reaction condition (for example, "25-O" refers to a reaction performed at $25^{\circ} \mathrm{C}$ in the presence of $\mathrm{O}_{2}$ ), similarly hereinafter. 


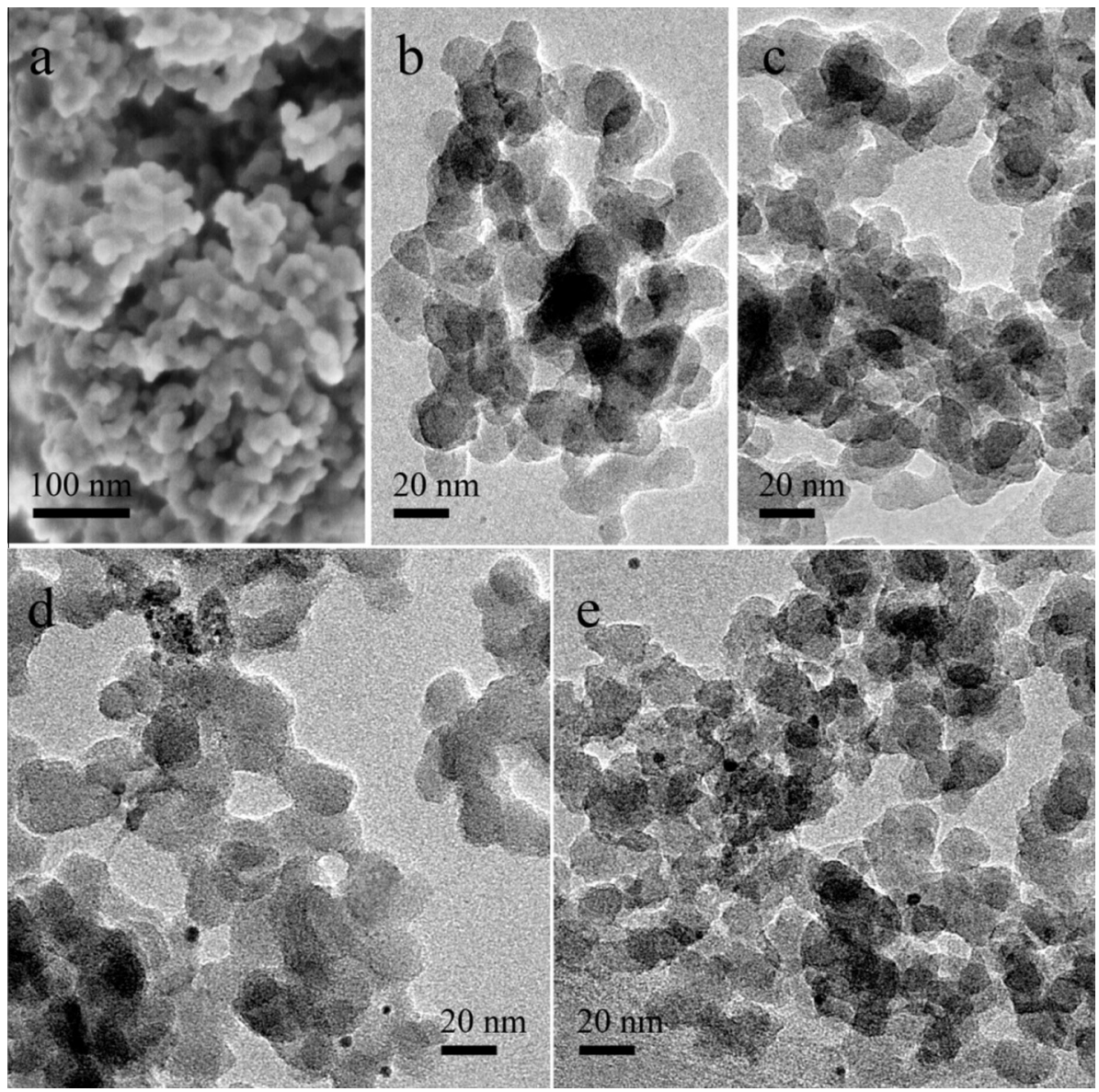

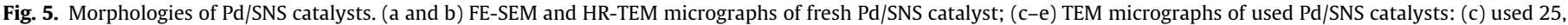
(d) used 25-O, and (e) used 50-0.

observed that the introduction of $\mathrm{O}_{2}$ into the reaction mixture enhanced the degree of conversion of 1 -butene to $47.6 \%$. 2Butene was the only detected product and no $\mathrm{CO}_{2}$ was produced. Moreover, $\mathrm{O}_{2}$ seemed to have no significant effect on the trans:cis ratio of 2-butene, so we hypothesize that $\mathrm{O}_{2}$ activates the reaction without breaking $\mathrm{C}-\mathrm{C}$ bonds or otherwise changing the reaction mechanism.

The effect of the $\mathrm{O}_{2}$ :1-butene ratio was also evaluated, and the results are shown in Fig. $3 \mathrm{~b}$. When the ratio of $\mathrm{O}_{2}: 1$-butene was $0.5: 1$, the yield increased to $57.2 \%$. Then the catalytic performance decreases a little with higher $\mathrm{O}_{2}$ :1-butene ratio.

\subsection{Reasons for the decrease in catalytic activity}

The activity of Pd/SNS catalyst somewhat decreased with reaction time. The transformation from a reductive to an oxidative valence in noble metals is thought to be one of the main causes for the deactivation of supported noble metal catalysts in heterogeneous reactions [35]. Fig. 4a showed the percent yield of 2butene over $2 \mathrm{~h}$ with sequential exposure to helium (He) and hydrogen $\left(\mathrm{H}_{2}\right)$ at different temperatures. Catalytic activity was evaluated for an additional hour after each exposure. Exposure to He failed to reactivate the catalysts, which eliminated the possibility of trace surface water poisoning the catalyst. However, the catalyst was reactivated again when exposed to $\mathrm{H}_{2}$ at lower temperatures. Other possible reasons for the observed decrease in catalytic activity, including Pd nanoparticles aggregation and carbon deposition, cannot be solved during these processes. Above

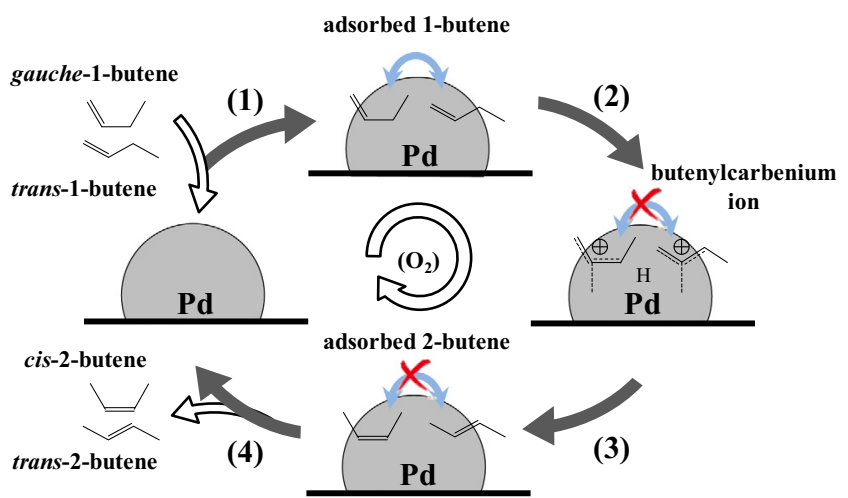

Fig. 6. Proposed reaction scheme for the isomerization of 1-butene to 2-butene over a Pd/SNS catalyst.

all, the oxidation of active sites is the primary reason for decreased catalytic activity.

Fig. 4b shows a Pd (3d) X-ray photoelectron spectrum (XPS) of a fresh $\mathrm{Pd} / \mathrm{SNS}$ catalyst. Only $\mathrm{Pd}^{0} \quad\left(3 d_{3 / 2}=341.6 \mathrm{eV}\right.$ and $\left.3 d_{5 / 2}=336.2 \mathrm{eV}\right)[36,37]$ was observed, suggesting that the Pd remained fully reduced during the preparation process. After the reaction, peaks corresponding to $\mathrm{PdO}$ appear, suggesting that $\mathrm{Pd}$ is partially oxidized. These peaks become more prominent when $\mathrm{O}_{2}$ was added to the reaction feed gas. Fig. 4c shows the $\mathrm{H}_{2}$ temperature-programmed reduction $\left(\mathrm{H}_{2}\right.$-TPR) patterns of $\mathrm{Pd} / \mathrm{SNS}$ catalyst. Compared with fresh Pd/SNS catalyst, broad peak emerges around $100{ }^{\circ} \mathrm{C}$, which confirmed with the XPS results. 
Table 1

Product distribution of different reaction gases over a Pd/SNS catalyst.

\begin{tabular}{lccc}
\hline \multirow{2}{*}{ Reaction gas } & \multicolumn{3}{l}{ Product distribution $(\%)^{\mathrm{a}}$} \\
\cline { 2 - 4 } & 1-Butene & Trans-2-butene & Cis-2-butene \\
\hline 1-Butene & 63.0 & 26.1 & 10.9 \\
Trans-2-butene & 0 & 100 & 0 \\
Cis-2-butene & 0 & 0 & 100
\end{tabular}

a The molar ratio of $\mathrm{O}_{2}: 1$-butene was $0: 1$ and the reaction temperature was $25^{\circ} \mathrm{C}$.

However, as shown in Fig. 4a, exposure to $\mathrm{H}_{2}$ failed to fully restore catalytic activity. In addition, the accelerated decrease in activity in the presence of $\mathrm{O}_{2}$ remains unexplained. To illustrate these problems, the morphologies of several Pd/SNS catalysts were studied by field-emission scanning electron microscopy (FE-SEM) and (HR-TEM), and the corresponding micrographs are shown in Fig. 5. As shown in Fig. 5a, the particle size of SNS is narrowly distributed (about $20 \mathrm{~nm}$ ), which agrees with the $\mathrm{D}_{\mathrm{BET}}$ data shown in Table S1. The SNS nanospheres were randomly arrayed in three dimensions, and the resulting disordered mesoporous framework provided an easy route for the diffusion of reactants and products $[38,39]$, thereby facilitating catalytic activity. Fig. 5b shows the Pd nanoparticles of a fresh catalyst with an average diameter of about $1.7 \mathrm{~nm}$. After running the reaction at $25^{\circ} \mathrm{C}$, the nanoparticles grew larger to about $2.1 \mathrm{~nm}$, as shown in Fig. 5c. In Fig. 5d, the addition of $\mathrm{O}_{2}$ further increased the degree of aggregation $(2.8 \mathrm{~nm})$, which led to a decrease in catalytic activity $[35,40]$. These results also imply that $\mathrm{O}_{2}$ may accelerate nanoparticle aggregation during the reaction. In addition, the Pd nanoparticles grew to $3.1 \mathrm{~nm}$ after running the reaction at $50{ }^{\circ} \mathrm{C}$, as shown in Fig. 5e. This explains the low catalytic activity observed at this slightly higher temperature.

\subsection{Reaction process}

Fig. 6 shows that the double-bond-shift isomerization of 1butene is a single molecular reaction and generally involves the following four consecutive steps as reported [15,18,19,41-44]: (1) gaseous 1-butene adsorbs onto the surface of Pd nanoparticles, $(2,3)$ adsorbed 1 -butene is converted to adsorbed 2-butene via a butenylcarbenium ion intermediate, and (4) 2-butene diffuses to the gas phase. Many researchers have reported a simple stepwise process for steps (2) and (3). First, butenylcarbenium ion intermediate is formed by abstraction of hydride, and then the anomeric carbon atom is attacked by the hydride to finish the catalytic cycle. During step (2), O species could promote the splitting of the $\mathrm{C}-\mathrm{H}$ bond, and further facilitate the 1-butene double-bond-shift isomerization reaction $[45,46]$. We conclude that is the reason for the adding of $\mathrm{O}_{2}$ could enhance the yield of 2-butene.

The stable conformers of gaseous 1-butene are trans- and gauche-type, with the methyl group eclipsing the $\mathrm{C}=\mathrm{C}$ double bond or skewed from this position by about $120^{\circ}$, respectively $[47,48]$. Because of the free rotation of the $\mathrm{C}-\mathrm{C}$ single bond, trans- and gauche-1-butene can freely interconvert in the gas phase with a trans:gauche ratio of about 1:2. Therefore, step (1) has no practical effect on the trans:cis ratio of the butenylcarbenium ion. In addition, geometric isomerization between trans and cis isomers is rare in the butenylcarbenium ion because of its extremely stable structure [25]. The data in Table 1 suggest that the titled reaction is irreversible and trans-2-butene or cis-2-butene does not transform into any isomer over Pd/SNS. Neither adsorbed nor gaseous 2butene is free to convert between the trans and cis isomers, which is different from other catalytic systems [24,44]. In other words, after step (2), once the "flat" butenylcarbenium ion formed, the geometry of the carbon skeleton cannot be altered. Thus, the geometry of the butenylcarbenium ion intermediate, which ultimately determines the final cis:trans ratio of the 2-butene product, must be determined during step (2).

Based on the above experiments and discussions, a reaction process for the isomerization of 1-butene to 2-butene over a $\mathrm{Pd}$ / SNS catalyst is proposed. Pd nanoparticles act as active sites for this irreversible reaction. 1-Butene is converted to 2-butene via a butenylcarbenium ion, and the trans:cis ratio of this ion determines the same ratio in the product. $\mathrm{O}_{2}$ accelerates this reaction but does not fundamentally change the reaction mechanism.

\section{Conclusions}

An efficient and practical approach for the isomerization of 1butene to 2-butene was realized at room temperature based on a silica nanospheres (SNS)-supported nano-Pd catalyst. This system exhibited a unique catalytic performance with no additional energy requirement. The yield of 2-butene was $37.0 \%$ at $25^{\circ} \mathrm{C}$ and the only detected product was 2-butene. Differs from previous reports, we found $\mathrm{Pd}^{+\delta}$ was inactive at the same reaction condition. The addition of $\mathrm{O}_{2}$ was shown to enhance the yield to $57.2 \%$ without the production of unwanted by-products such as $\mathrm{CO}_{2}$.

The surface acidity of catalyst had remarkably influences on catalytic activity. The activity of a used catalyst could be recovered by exposure to $\mathrm{H}_{2}$ gas and consequent reduction.

A reaction process was proposed in which reaction temperature influences the trans: cis ratio of a butenylcarbenium ion intermediate, which ultimately determines that of the 2-butene product.

\section{Acknowledgments}

This work was financially supported by the National Natural Science Foundation $(21337003,21477149,21577158)$, the Strategic Priority Research Program of the Chinese Academy of Sciences (XDB05050200) and Special Environmental Protection Foundation for Public Welfare Project (201309073).

\section{Appendix A. Supplementary data}

Supplementary data associated with this article can be found, in the online version, at http://dx.doi.org/10.1016/j.cej.2016.04.040.

\section{References}

[1] A. Corma, A Martínez, Chemistry, catalysts, and processes for isoparaffinolefin alkylation: actual situation and future trends, Catal. Rev. 35 (4) (1993) 483-570.

[2] R.B. Gore, W.J. Thomson, Pulsed gas-phase alkylation of isobutane/2-butene over sulfated zirconia, Appl. Catal. A Gen. 168 (1) (1998) 23-32.

[3] S.J. Huang, S.L. Liu, W.J. Xin, J. Bai, S.J. Xie, Q.X. Wang, L.Y. Xu, Metathesis of ethene and 2-butene to propene on $\mathrm{W} / \mathrm{Al}_{2} \mathrm{O}_{3}-\mathrm{HY}$ catalysts with different $\mathrm{HY}$ contents, J. Mol. Catal. A Chem. 226 (2005) 61-68.

[4] J.C. Mol, Industrial applications of olefin metathesis, J. Mol. Catal. A Chem. 213 (2004) 39-45.

[5] W.Q. Xu, Y.G. Yin, S.L. Suib, J.C. Edwards, C.L. O’young, n-Butene skeletal isomerization to isobutylene on shape selective catalysts: ferrierite/ZSM-35, J. Phys. Chem. 99 (1995) 9443-9451.

[6] J. HouŽViČKa, V. Ponec, Skeletal isomerization of n-butene, Catal. Rev. 39 (4) (1997) 319-344.

[7] B.T. Yang, J.G. Jiang, H. Xu, Y.M. Liu, H.G. Peng, P. Wu, Selective skeletal isomerization of 1-butene over FER-type zeolites derived from PLS-3 lamellar precursors, Appl. Catal. A 455 (2013) 107-113.

[8] M.A. Asensi, A. Corma, A. Martinez, Skeletal isomerization of 1-butene on MCM-22 zeolite catalyst, J. Catal. 158 (1996) 561-569.

[9] I. Lee, F. Zaera, Selectivity in platinum-catalyzed cis-trans carbon-carbon double-bond isomerization, J. Am. Chem. Soc. 127 (2005) 12174-12175.

[10] B. Brandt, J.H. Fischer, W. Ludwig, J. Libuda, F. Zaera, S. Schauermann, H.J. Freund, Isomerization and hydrogenation of cis-2-butene on Pd model catalyst, J. Phys. Chem. C 112 (2008) 11408-11420.

[11] F. Delbecq, F. Zaera, Origin of the selectivity for trans-to-cis isomerization in 2 butene on Pt(111) single crystal surfaces, J. Am. Chem. Soc. 130 (2008) 1492414925. 
[12] I. Lee, F. Zaera, Nanoparticle shape selectivity in catalysis: butene isomerization and hydrogenation on platinum, Top. Catal. 56 (2013) 12841298.

[13] D.M. Golden, K.W. Egger, S.W. Benson, Iodine-catalyzed isomerization of olefins. I. Thermodynamic data from equilibrium studies of positional and geometrical isomerization of 1-butene and 2-butene, J. Am. Chem. Soc. 86 (24) (1964) 5416-5420.

[14] M. Perissinotto, M. Lenarda, L. Storaro, R. Ganzerla, Solid acid catalysts from clays: acid leached metakaolin as isopropanol dehydration and 1-butene isomerization catalyst, J. Mol. Catal. A: Chem. 121 (1997) 103-109.

[15] J. Puriwat, W. Chaitree, K. Suriye, S. Dokjampa, P. Praserthdam, J. Panpranot, Elucidation of the basicity dependence of 1 -butene isomerization on $\mathrm{MgO} / \mathrm{Mg}$ $(\mathrm{OH})_{2}$ catalysts, Catal. Commun. 12 (2010) 80-85.

[16] J.H. Li, R.J. Davis, On the use of 1-butene double-bond isomerization as a probe reaction on cesium-loaded zeolite X, Appl. Catal. A 239 (2003) 59-70.

[17] M. Pu, B.H. Chen, H.X. Wang, A DFT study on the double bond migration of butene catalyzed by ionic pair of 1-ethyl-3-methyl-imidazolium fluoride, Chem. Phys. Lett. 410 (2005) 441-445.

[18] L.X. Xie, D.J. Zhang, X.J. Liu, X. Zhang, P.P. Duan, Double bond isomerization of butene catalyzed by 1-ethyl-3-methyl-imidazolium chloride: concerted or stepwise mechanism?, Comput Theory Chem. 963 (2011) 344-347.

[19] P. Amigues, J. Gaillard, J.F.L. Page, R. Stern, Process for isomerizing 1-butene to 2-butene, US Patent (1978) No. 87957978 A.

[20] K. Muñiz, High-oxidation-state palladium catalysis: new reactivity for organic synthesis, Angew. Chem. Int. Ed. 48 (2009) 9412-9423.

[21] X.F. Wu, P. Anbarasan, H. Neumann, M. Beller, From noble metal to nobel prize: palladium-catalyzed coupling reactions as key methods in organic synthesis, Angew. Chem. Int. Ed. 49 (2010) 9047-9050.

[22] H.Z. Liu, T. Jiang, B.X. Han, S.G. Liang, Y.X. Zhou, Selective phenol hydrogenation to cyclohexanone over a dual supported Pd-Lewis acid catalyst, Science 326 (2009) 1250-1252.

[23] A. Sen, T.W. Lai, Mechanism of palladium(II)-catalyzed carbon-carbon double bond isomerization in olefins, Inorg. Chem. 23 (1984) 3257-3258.

[24] S. Carrá, V. Ragaini, On the mechanism of 1-butene isomerization on supported palladium, J. Catal. 10 (1968) 230-237.

[25] K. Hashimoto, Y. Masuda, H. Kominami, Photocatalytic isomerization of 1 butene over palladium-loaded titanium(IV) oxide particles: Lewis acid-like features of the photocatalyst, ACS Catal. 3 (2013) 1349-1355.

[26] Y. Li, W.P. Liao, Z.H. Suo, Influence of $\mathrm{KOH}$ modification on $\mathrm{TiO}_{2}$ structure and $\mathrm{Au} / \mathrm{TiO}_{2}$ catalyst activity in $\mathrm{CO}$ oxidation, J. Fuel Chem. Technol. 39 (2011) 4753.

[27] T.W. Kim, F. Kleitz, B. Paul, R. Ryoo, MCM-48-like large mesoporous silicas with tailored pore structure: facile synthesis domain in a ternary triblock copolymer-butanol-water system, J. Am. Chem. Soc. 127 (2005) 7601-7610.

[28] L.S. Zhong, J.S. Hu, Z.M. Cui, L.J. Wan, W.G. Song, In-Situ loading of noble metal nanoparticles on hydroxyl-group-rich titania precursor and their catalytic applications, Chem. Mater. 19 (2007) 4557-4562.

[29] Y.C. Wei, J. Liu, Z. Zhao, C.M. Xu, A.J. Duan, G.Y. Jiang, Structural and synergistic effects of three-dimensionally ordered macroporous $\mathrm{Ce}_{0.8} \mathrm{Zr}_{0.2} \mathrm{O}_{2}$-supported Pt nanoparticles on the catalytic performance for soot combustion, Appl. Catal. A 453 (2013) 250-261.
[30] H.L. Wang, W.Y. Xin, Surface acidity of H-Beta and Its catalytic activity for alkylation of benzene with propylene, Catal. Lett. 76 (3-4) (2001) 225-229.

[31] L.G. Wang, Y. Qi, Y.X. Wei, D.R. Fang, S.H. Meng, Z.M. Liu, Research on the acidity of the double-function catalyst for DME synthesis from syngas, Catal. Lett. 106 (1-2) (2006) 61-66.

[32] B.B. Bardin, J.D. Robert, Effect of water on silica-supported phosphotungstic acid catalysts for 1-butene double bond shift and alkane skeletal isomerization, Appl. Catal. A Gen. 200 (1-2) (2000) 219-231.

[33] Y.K. Park, S.J. Kim, N. You, J. Cho, S.J. Lee, J.H. Lee, J.K. Jeon, $\mathrm{MoO}_{3} / \mathrm{SiO}_{2}$ catalysts for double bond migration of 2-butene, J. Ind. Eng. Chem. 17 (2) (2011) 186190.

[34] D.M. Hasenberg, M.D. Refvik, M.S. Matson, Process to isomerize 1-butene to 2butene, US Patent (2005) No. 6852901 B2.

[35] P. Albers, J. Pietsch, S.F. Parker, Poisoning and deactivation of palladium catalysts, J. Mol. Catal. A: Chem. 173 (2001) 275-286.

[36] F. Wang, G.X. Lu, Regulating role of cobalt oxide on deleterious chlorine ion over PdO/SiO 2 for CO oxidation, J. Phys. Chem. C 113 (2009) 17070-17075.

[37] H.Y. Chen, Y. Li, F.B. Zhang, G.L. Zhang, X.B. Fan, Graphene supported Au-Pd bimetallic nanoparticles with core-shell structures and superior peroxidaselike activities, J. Mater. Chem. 21 (2011) 17658-17661.

[38] A.K. Sinha, S. Seelan, S. Tsubota, M. Haruta, A three-dimensional mesoporous titanosilicate support for gold nanoparticles: vapor-phase epoxidation of propene with high conversion, Angew. Chem. Int. Ed. 43 (2004) 1546-1548.

[39] B.C. Liu, S.L. Yu, Q. Wang, W.T. Hu, P. Jing, Y. Liu, W.J. Jia, Y.X. Liu, L.X. Liu, J. Zhang, Hollow mesoporous ceria nanoreactors with enhanced activity and stability for catalytic application, Chem. Commun. 49 (2013) 3757-3759.

[40] W. Gao, N. Guan, J. Chen, X. Guan, R. Jin, H. Zeng, Z. Liu, F. Zhang, Titania supported $\mathrm{Pd}-\mathrm{Cu}$ bimetallic catalyst for the reduction of nitrate in drinking water, Appl. Catal. B Environ. 46 (2003) 341-351.

[41] C.M. Wang, Y.D. Wang, J. Dong, S. Liu, Z.K. Xie, Structure sensitivity of double bond isomerization of butene over MgO surfaces: a periodic DFT study, Comput. Theory Chem. 974 (2011) 52-56.

[42] M. Boronat, P. Viruela, A Corma, Theoretical study of the mechanism of zeolite-catalyzed isomerization reactions of linear butenes, J. Phys. Chem. A 102 (1998) 982-989.

[43] Y.H. Guo, M. Pu, L.Y. Liu, H.F. Li, B.H. Chen, Theoretical study of two pathways of double-bond isomerization of pentene catalyzed by zeolites, Comput. Mater. Sci. 42 (2008) 179-185.

[44] F. Garcia-Ochoa, A. Santos, Isomerization of 1-butene on silica-alumina: kinetic modeling and catalyst deactivation, AlChE J. 41 (2) (1995) 286-300.

[45] C.V. Gaskell, C.M.A. Parlett, M.A. Newton, K. Wilson, A.F. Lee, Redox-controlled crotyl alcohol selective oxidation: in situ oxidation and reduction dynamics of catalytic Pd nanoparticles via synchronous XANES/MS, ACS Catal. 2 (2012) $2242-2246$.

[46] R. Neumann, A.M. Khenkin, Molecular oxygen and oxidation catalysis by phosphovanadomolybdates, Chem. Commun. 24 (2006) 2529-2538.

[47] J.R. Durig, D.A.C. Compton, Spectroscopic and thermodynamic study of the conformational properties and torsional potential functions of 1-butene, J. Phys. Chem. 84 (1980) 773-781.

[48] W.L. Jorgensen, J.D. Madura, C.J. Swenson, Optimized intermolecular potential functions for liquid hydrocarbons, J. Am. Chem. Soc. 106 (1984) 6638-6646. 